\title{
Distal Renal Tubular Acidosis
}

National Cancer Institute

\section{Source}

National Cancer Institute. Distal Renal T ubular Acidosis. NCI Thesaurus. Code C123217.

Failure of the renal tubules of the kidney to excrete urine of sufficient acidity, resulting in metabolic acidosis. 